F O U N D A T I O N

Vol. 41

DE DE GRUYTER
$\mathrm{O}$

C O M P U T I N G
\[ (2016) \]

D E C I S I O N

DOI: $10.1515 /$ fcds-2016-0005
S C I E N C E S

No. 2

ISSN 0867-6356

e-ISSN 2300-3405

\title{
IN MEMORIAM \\ PROFESSOR SOLOMON MARCUS
}

\author{
Jerzy Stefanowski *
}

We are deeply saddened to inform you that on March 17, 2016, a famous Romanian scholar, Professor Solomon Marcus passed away at the age of 91.

Professor Solomon Marcus had been a member of the Editorial Board of Foundations of Computing and Decision Sciences since its launch in 1975 and had been supporting our journal throughout the succeeding decades. Below we would briefly like to recall his biography and highlights of his scientific career.

He was born on March 1, 1925, in Bacău, Romania. From an early age he had to live through a difficult period of dictatorships and the Second World War. Graduated from elementary school and high school in Bacău, he was classified the first at the final examination ("bacalaureat") in 1944. Afterwards, he completed his studies at the University of Bucharest's Faculty of Science, Department of Mathematics, in 1949.

Solomon Marcus obtained his PhD in Mathematics in 1956 from the University of Bucharest, with a thesis on the monotonic functions of two variables, written under supervision of professor Miron Nicolescu. He received a title of State Doctor in Sciences in 1968 at the same university. He had worked as an Assistant professor since 1950, Lecturer since 1955, Associate Professor since 1964, and became a Full Professor in 1966 (Emeritus in 1991). All these positions were held in the Faculty of Mathematics, University of Bucharest. He had also been a Corresponding Member of Romanian Academy since April 1993, and Full Member of the Romanian Academy (Academician) since December 2001.

His research and teaching activities related to the fields of mathematical analysis, theoretical computer science, measure theory, general topology, linguistics, history and philosophy of mathematics, poetics, semiotics, applications of mathematics to natural and social sciences. He also published numerous papers on various cultural topics: poetics, art, theatre, philosophy and history of science and education.

As a mathematician he investigated several problems in the field of Mathematical Analysis and related areas. A summary of his major contributions is available at the web page [6].

Furthermore, he is recognized as one of the founders of mathematical linguistics and of mathematical poetics. Gheorghe Păun and Grzegorz Rosenberg discuss in

${ }^{*}$ Editor in Chief of Foundations of Computing and Decision Sciences journal 
their essay [4] his noteworthy book "Mathematical Linguistics. Mathematical Models in Linguistics" (originally published in Romanian in 1963; the English and French translations in 1967). They also mention other pioneering works on finite grammars, automata and language theory. In particular, in 1969 he introduced contextual grammars (by now often referred to as Marcus grammars), which influenced many researchers.

During the following years he made major contributions to semiotics. He wrote several influential works in this field, e.g.: The semiotics of folklore. A linguistmathematic approach; Signs about signs; The mathematical semiotics of the visual arts; Art and science; Modes of thinking, and the book Universal Paradigms - which is a synthesis of his thoughts [7].

He was also deeply interested in education of young people. Besides authoring scientific papers, he participated in several TV and radio programs, was involved in mathematical training camps for high school students, and visited several schools.

Professor Solomon Marcus was an author or co-author of over 50 books in Romanian, English, French, German, Italian, Spanish, Russian, Greek, Hungarian, Czech, Serbo-Croatian, and about 400 research articles in specialized journals. He also edited over 40 collective volumes, and spoke over 250 invited lectures at various conferences or universities in Europe, Americas, and Asia.

In addition to his position as professor and researcher, he served in a number of organizational capacities being Vice President of the International Association for Semiotic Studies (1989- 1999), Honorary President of the Balkan Semiotic Society (since 2001), Member of the Executive Committee of the International Association for Semiotic Studies, Honorary Member of the International Association for Visual Semiotics, Honorary Member of the Toronto Semiotic Circle, of Como (Italy) Semiotic Circle and of the Hungarian Semiotic Society, Honorary member of the Romanian Mathematical Society, Member of the leading Council of the Romanian Linguistic Society, Vice-president of the Romanian Semiotic Society, Member of the Romanian Committee for the Club of Rome, and Honorary member of the Society Eratosthene, Switzerland.

He also received numerous prizes in Romania and abroad.

Working in so many diverse fields, Solomon Marcus can be named a Renaissance man. Although he represented a mathematical rigor, he was deeply interested in theatre, poetry and many other universal paradigms. As Nicoleta Popa Blanariu wrote in her memorial paper "His career was built, I would say, on the coherence of heterogeneity. He saw connections where the tradition of the Sciences and the $\mathrm{Hu}-$ manities had placed borders that could only be transgressed at the risk of losing one's credibility in the academic world. Solomon Marcus encouraged, even legitimized this interdisciplinary dialogue by means of which study domains could become mutually supportive" [1].

Professor Marcus was a modest and considerate person. Being open to new ideas, he radiated enthusiasm and kind encouragement to anyone he talked to. He entered the international editorial board of "Foundations of Control Engineering" (former name of FCDS) since vol. 1, no. 2, 1976, and contributed a lot to the development of the journal, both as an author and as a reviewer. He was also very enthusiastic 
about the idea of rough sets, introduced by his friend Professor Zdzisław Pawlak, and also participated at some rough set conferences. In particular, he appreciated the extension of the rough set concept aiming at reasoning about ordinal data dominance-based rough set approach. His relations with Polish researchers were very lively indeed.

More information on Professor Solomon Marcus can be found in a book "People and Ideas in Theoretical Computer Science" [2]. Furthermore, the various selection of his papers in English followed by some interviews and a brief autobiography were published in 2007 in a book entitled "Words and Languages Everywhere" [3].

He won the respect and admiration of many people who met him. He will be greatly missed for his approachability and friendly personality.

\section{References}

[1] Blanariu N.P., In memoriam Solomon Marcus. Southern Semiotic Review 7, 2016 (1), 11-12.

[2] Calude C.S., ed., People and ideas in Theoretical Computer Science. Springer 1999. $163-176$

[3] Marcus S., Words and languages every-where. Milano: Polimetrica s.a.s., 2007.

[4] Paun G., Rosenberg G., A Naturally Unique Scholar: Solomon Marcus - a Man Who Was Never Bored. Annals of the University of Bucharest (mathematical series) 6 (LXIV) 2015, 15--18.

[5] Wikipedia entry on Solomon Marcus - https://en.wikipedia.org/wiki/ Solomon_Marcus

[6] Academician Solomon Marcus web page at the University of Bucharest - http: //fmi.unibuc.ro/ro/marcus_solomon

[7] Semiosis in communication - web page Phttp://centrucomunicare.ro/ semiosis/semiosisc_2016.html Including the special text "Hide and seek"... with Solomon Marcus and Umberto Eco, from IASS-AI Association. 